\title{
Study of IYCF Indicators on Practices and Knowledge of Mothers in Rural Areas
}

\author{
Taslima Arzu ${ }^{1, *}$, Ariful Kabir Sujan ${ }^{2}$, Farha Matin Juliana ${ }^{3}$, Sabir Hossain ${ }^{3}$ \\ ${ }^{1}$ Jahangirnagar University, Department of Biochemistry and Molecular Biology, Savar, Dhaka, Bangladesh \\ ${ }^{2}$ Technical Manager, Nutrition Department, Save the Children, Bangladesh \\ ${ }^{3}$ Department of Biochemistry and Molecular Biology, Jahangirnagar University, Savar, Dhaka, Bangladesh \\ *Corresponding author: tanu04@gmail.com
}

\begin{abstract}
The IYCF practices have a great impact on the physical and mental development of the child. The objective of this study was to study the knowledge and compliance to IYCF practices along. The lactating mothers with the children in the age group 0-23 months were studied. Mother's knowledge level is average about IYCF components; $55.5 \%$ mothers have proper knowledge about IYCF practice. $70.9 \%$ mothers have knowledge on initiation of breast-feeding within an hour of birth while $50.7 \%$ of the mothers initiated breast-feeding within an hour after birth. Exclusive breast-feeding for 6 months was practiced by the mothers of $69.1 \% .69 .1 \%$ of the mothers told that complimentary feeding should start at 6 months.64.6\% of the mother will continue breast fed for 2 years of infants and $72.5 \%$ mothers practicing age appropriate meal frequency but only 37.3 children have minimum diet diversity.
\end{abstract}

\section{Keywords: Infant and Young Child Feeding (IYCF), Brest feeding, complementary feeding, lactating mother}

Cite This Article: Taslima Arzu, Ariful Kabir Sujan, Farha Matin Juliana, and Sabir Hossain, "Study of IYCF Indicators on Practices and Knowledge of Mothers in Rural Areas.” American Journal of Public Health Research, vol. 6, no. 3 (2018): 130-133. doi: 10.12691/ajphr-6-3-1.

\section{Introduction}

The optimal infant and young child feeding practices during the first 2 years of life is of paramount importance as this period is the "critical window" for the promotion of health, good growth, behavioral and cognitive development. Optimal infant and young child feeding practices include: i) Initiation of breast-feeding within 1 hour of birth, ii) Exclusive breast-feeding for the first 6 months iii) Continuation of breast-feeding for 2 years or more, along with iv) Nutritionally adequate, safe, ageappropriate, responsive complementary feeding starting at 6 months. [1] Breast-feeding strengthens emotional security and affection creating a strong bond between the mother and the child, which in turn promotes psychosocial development of a child. To ensure good nutrition status of the infant as well as the mother, maternal nutrition plays a vital role. Breast-feeding is nature's way of nurturing the child. It provides learning and development opportunities to the infant. Breast milk also leads to increased intelligence quotients and better visual acuity due to the presence of special fatty acids in it. [2]

Approximately, 1.4 million deaths of children under the age of 5 years worldwide can be attributed to suboptimal breast-feeding. Almost $6 \%$ of under-five mortality can be pre- vented by the timely introduction of complementary feeding. [3] It was estimated that about one-fifth of overall under-five mortality can be averted if $90 \%$ infants are covered with an inclusive package of interventions to promote, protect, and support the optimal infant young child feeding (IYCF) practices. [3] A large proportion of children become vulnerable to stunting, poor cognitive development, and significantly increased risk of infectious diseases, such as, diarrhea and acute respiratory infection due to the poor complementary feeding practices [4].

It has been established that because of the best bioavailable iron in breast milk, exclusive breast-feeding prevents anemia and infections particularly the diarrheal infections in the child. The need of introducing cereal-based foods in the diet of infant after the age of 6 months can be correlated with the fact that enzyme amylase appears in the seventh month of the infant. [5] The mother's risk for excess postpartum bleeding is decreased if breast-feeding is initiated early, which in turn lowers the risk for anemia. Exclusive breast-feeding delays next pregnancy boosts mother's immunity and reduces the insulin needs of diabetic mothers. Breast-feeding also provides protection from breast and ovarian cancers and osteoporosis. [6] This has an enormous impact in a developing country, like India, with a high burden of disease and low access to safe water and sanitation. The recent studies conducted even in developed countries have also emphasized the role of IYCF practices in reducing child mortality. [7] A global strategy for infant- and young child-feeding has been devised by the World Health Organization (WHO) and United Nations Children Fund. Based on these guiding principles, the Government of India, in collaboration with international agencies, has adopted the culturally acceptable IYCF guidelines, which were incorporated in the Integrated Management of Neonatal and Childhood Illness Programme. [8] 
These guidelines recognize appropriate infant feeding practices to be crucial for improving nutrition status and decreasing infant mortality in all countries. WHO offers three recommendations for IYCF practices for children aged 6-23 months: continued breast-feeding or feeding with appropriate calcium-rich foods if not breast-fed; feeding solid or semisolid food for a minimum number of times per dayaccording to age and breast-feeding status; and including foods from a minimum number of food groups per day according to breast-feeding status.

Bangladesh Demographic and Health Survey (BDHS 2014) have provided useful national- and state-level information on the IYCF practices. [9] Available data showed a gross interstate variation. However, the BDHS was not designed to provide district-level data. According to the BDHS-2014 data Fifty-five percent of infants under age 6 months are exclusively breastfed. The Multiple Indicator Cluster Survey 2012-13 reportedlower exclusive breastfeeding rates of 56 percent [10]. Overall, 26 percent of breastfed children age 6-23 months are given the recommended four or more food groups, and 63 percent are fed at least the minimum number of times.

According to the Multiple Indicator Cluster Survey 2012-13 (MICS-2012-13) early initiation of breast feeding (within an hour of delivery) is $57.4 \%$., continued breast feeding up to 2 years $87.5 \%$. [10]

With this background, this study was undertaken to assess the IYCF knowledge and practices with special emphasis on IYCF indicators, among children aged less than 2 years among16 rural areas or villages at Maligasa Union, Pabna district, Bangladesh.

\section{Methods and Materials}

It was a convenient sample survey study conducted on February, 2018, at Maligasa Union, Pabna district, Bangladesh. The union caters population of about 25000 in the field practice area by providing primary and promotive health care. Study population comprised of mothers having children of age group 0-23 months. A total of 353 eligible mothers were approached through house-to-house visit to participate in the study by convenient sampling method. They were informed about the purpose of study and informed consent was obtained from the mothers. The data were collected by interview method using a pretested schedule. Data were analyzed through Epi info and SPSS software. WHO indicators for assessing infant and child feeding practices were used. A pretested questionnaire mainly based on the standard questionnaire on IYCF practices given by WHO was used for data collection. [11]

These questions provide the information needed to calculate the key indicators of IYCF. As per WHO recommendations, information was collected about the child's diet in the previous 24 hours, which included the type of food items and the number of times they had consumed. Food items were categorized into seven types, that is, cereals, legumes and nuts, dairy products, meat products, egg, vitamin A-rich fruits and vegetables, and other fruits and vegetables. Children less than 24 months were included in the study after obtaining verbal informed consent from the mothers.

\section{Results and Discussion}

Out of the 353 children studied, 51.3\% were boys and $48.7 \%$ were girls. Table 1 gives the complete information regarding the sociodemographic profile of the population studied.

Table 1. Socio-demographic profile of the studied population

\begin{tabular}{|c|c|c|c|}
\hline Parameter & Categories & $\begin{array}{c}\text { Frequency } \\
(\mathrm{N}=353)\end{array}$ & (\%) \\
\hline \multirow{2}{*}{ Gender } & Male & 181 & 51.3 \\
\hline & Female & 172 & 48.7 \\
\hline \multirow{2}{*}{$\begin{array}{l}\text { Age of the kid } \\
\text { (in months) }\end{array}$} & $6-11$ & 39 & 11.1 \\
\hline & $12-23$ & 314 & 88.9 \\
\hline \multirow{2}{*}{ Religion } & Muslim & 349 & 98.9 \\
\hline & Hindu & 04 & 1.1 \\
\hline \multirow{4}{*}{$\begin{array}{c}\text { Mother's educational } \\
\text { qualification }\end{array}$} & B.A. or B.Sc or above & 20 & 5.7 \\
\hline & Intermediate & 64 & 18.1 \\
\hline & High School & 126 & 35.7 \\
\hline & $\begin{array}{c}\text { Primary School \& } \\
\text { bellow }\end{array}$ & 143 & 40.5 \\
\hline \multirow{4}{*}{$\begin{array}{l}\text { Mother's knowledge } \\
\text { assessment status }\end{array}$} & $\begin{array}{l}\text { Excellent (100\% } \\
\text { knowledge) }\end{array}$ & 51 & 14.4 \\
\hline & $\begin{array}{l}\text { Good (60-80\% } \\
\text { knowledge) }\end{array}$ & 145 & 41.1 \\
\hline & $\begin{array}{c}\text { Average (40-60\% } \\
\text { knowledge) }\end{array}$ & 151 & 42.8 \\
\hline & $\begin{array}{c}\text { Below average (below } \\
40 \% \text { knowledge) }\end{array}$ & 06 & 1.7 \\
\hline
\end{tabular}

Table 2. Summary of the knowledge to key IYCF Practices

\begin{tabular}{|c|c|c|c|}
\hline Component & Knowledge & Frequency & $(\%)$ \\
\hline \multirow{4}{*}{$\begin{array}{l}\text { Timely Initiation of } \\
\text { Breast Feeding (<1 } \\
\text { hour from Birth) }\end{array}$} & Don't Know & 4 & 1.1 \\
\hline & After $3 / 4$ days & 12 & 3.4 \\
\hline & After $8 / 10$ hours & 88 & 24.9 \\
\hline & Immediately & 249 & 70.6 \\
\hline \multirow[b]{2}{*}{ What is colostrum } & Don’t Know & 57 & 16.1 \\
\hline & $\begin{array}{c}\text { Yellowish secretion after } \\
\text { delivery }\end{array}$ & 296 & 83.9 \\
\hline \multirow{4}{*}{$\begin{array}{l}\text { Benefits of } \\
\text { colostrum for baby } \\
\text { (Multiple response) }\end{array}$} & Don’t Know & 52 & 14.7 \\
\hline & Good for health & 176 & 49.9 \\
\hline & Baby's first vaccine & 198 & 56.1 \\
\hline & Increase immunity & 91 & 25.8 \\
\hline \multirow{3}{*}{$\begin{array}{l}\text { Benefits of } \\
\text { colostrum for } \\
\text { mother \& Family } \\
\text { (Multiple response) }\end{array}$} & Don't Know & 52 & 14.7 \\
\hline & No cost for family & 232 & 65.7 \\
\hline & Good for mother's health & 190 & 53.8 \\
\hline \multirow{4}{*}{$\begin{array}{l}\text { Exclusive Breast } \\
\text { Feeding (for } 6 \\
\text { months) }\end{array}$} & Don't know & 12 & 3.5 \\
\hline & Up to 5 months & 59 & 16.7 \\
\hline & Up to 6 months & 249 & 70.5 \\
\hline & Up to 1 year & 33 & 9.3 \\
\hline \multirow{4}{*}{$\begin{array}{l}\text { Timely Initiation of } \\
\text { Complimentary } \\
\text { Feeding (at } 6 \\
\text { months) }\end{array}$} & Don’t know & 28 & 7.9 \\
\hline & 4-5 months & 57 & 16.1 \\
\hline & After 6 months & 249 & 70.5 \\
\hline & After 9 months & 19 & 5.5 \\
\hline \multirow{3}{*}{$\begin{array}{l}\text { Continued Breast } \\
\text { Feeding (at least } 2 \\
\text { Years) }\end{array}$} & As long as baby drink & 62 & 17.6 \\
\hline & Up to 2 years & 228 & 64.6 \\
\hline & Up to 1 year & 63 & 17.8 \\
\hline
\end{tabular}


Table 3. Summary of the compliance to key IYCF Practices

\begin{tabular}{|l|c|c|c|}
\hline Component & Compliance & Frequency & (\%) \\
\hline \multirow{2}{*}{$\begin{array}{l}\text { Timely Initiation of } \\
\text { Breast Feeding (<1 hour } \\
\text { from Birth) }\end{array}$} & Within 1 hour & 179 & 50.7 \\
\cline { 2 - 4 } & Within 24 hours & 111 & 31.4 \\
\cline { 2 - 4 } & After 2/3 days & 63 & 17.9 \\
\hline \multirow{2}{*}{$\begin{array}{l}\text { How often you } \\
\text { breastfeed your children }\end{array}$} & 8-12 times a day & 267 & 75.6 \\
\cline { 2 - 4 } & 6-8 times a day & 67 & 19.0 \\
\cline { 2 - 4 } & When baby cry & 19 & 5.4 \\
\hline \multirow{2}{*}{$\begin{array}{l}\text { Exclusive Breast } \\
\text { Feeding (for over 6 } \\
\text { months only) }\end{array}$} & Up to 4-5 months & 78 & 22.1 \\
\cline { 2 - 4 } & Up to 6 months & 244 & 69.1 \\
\cline { 2 - 4 } & Up to 1 Years & 31 & 8.8 \\
\hline $\begin{array}{l}\text { Minimum diet diversity } \\
\text { of Complementary } \\
\text { feeding (at least 4 food } \\
\text { groups) }\end{array}$ & Acceptable & 133 & 37.7 \\
\cline { 2 - 4 } & Not acceptable & 220 & 62.3 \\
\hline $\begin{array}{l}\text { Age Appropriate Meal } \\
\text { Frequency }\end{array}$ & Acceptable & 256 & 72.5 \\
\cline { 2 - 4 } & Not acceptable & 97 & 27.5 \\
\hline
\end{tabular}

\subsection{Infant and Young Child Feeding (IYCF) Knowledge of the Mother}

The knowledges of the mothers on Infant and Young Child Feeding (IYCF) components were very good in terms the general context of Bangladesh. Most of the mothers have knowledge on best practices of IYCF components lies in average categories (55.5\% mothers with knowledge of $60-100 \%$ information about IYCF (14.4\% mothers know all information about IYCF and $41.1 \%$ mothers know $80 \%$ information) and $42.8 \%$ mother have average knowledge about IYCF practice. $70.6 \%$ of mothers have proper knowledge about timely initiation of breast feeding within one hour of birth. 83.9\% Mothers knew that what is colostrum. $70.5 \%$ mothers have knowledge about the continuation time of exclusive breast feeding up to 6 months of child's age and still 29.5\% mothers know wrong continuation time (don't know 3.5\%, up to 5 months $16.7 \%$ and up to 1 year 9.3\%). The knowledge about the timing of starting complementary feeding for the children of the mothers was quite good. $70.5 \%$ of the mothers knew the exact timing of starting complementary feeding (after 6 months of baby's age). $64.6 \%$ mothers knew that breast feeding should continue up to 2 years of child's age.

\subsection{Infant and Young Child Feeding (IYCF) Practices of the Mother}

An epidemiological evidence of a causal association between early initiation of breast-feeding and reduced infection-specific neonatal mortality has also been documented. [12] The Survey result shows that 50.7\% children were initiated breast feeding within one hour of delivery.

Exclusive breast-feeding was done by $69.1 \%$ of 189 children over 6 months of age. This was far better than the figures reported by BDHS-2014 data, at national level (55\%). [9]

Minimum dietary diversity (MDD) indicator is the proportion of children of 6-23 months of age who receive foods from four or more food groups from a total of seven food groups, such as, dairy products, legumes and nuts, flesh foods, eggs, vitamin A-rich fruits and vegetables, cereals and tubers, and other fruits and vegetables. [13] This indicator reveals whether the child is receiving a complete and balanced diet or not. MDD was observed in only 37.7\% children between 6 and 23 months age group.

Minimum Meal Frequency (MMF) indicator is the proportion of breast-fed and non-breast-fed children aged 6-23 months who receive solid, semisolid, or soft foods (but also including milk feeds for non-breast-fed children) the minimum number of times or more. [13] For breast-fed children, the minimum number of times varies with age (two times if 6-8 months and three times if 9-23 months). For non-breast-fed children, the minimum number of times does not vary by age (four times for all children aged 6-23 months). MMF was observed in the majority (72.5\%) of children aged 6-23 months is acceptable.

\section{Recommendation}

The IYCF practices are strongly influenced by what people know, think and believe and also affected by social circumstances and economic factors. Effective communication for behavioral change is necessary for ensuring optimal infant feeding. Awareness regarding IYCF practices and their benefits in Maternal and Child Health $(\mathrm{MCH})$ is poor leading to poor compliance. It is important to educate mothers during the antenatal visits. The situation can be improved by training of grass root health workers on IYCF policies of WHO and MoHFW, Govt. of Bangladesh, stressing on the benefits of appropriate feeding practices by the hospitals, Health \& Family Welfare Centre (H\&FWC), Union Health Sub Centre (USC) and Community Clinic and making these services universally available along with intensive IEC (Information, Education \& Communication) efforts to generate demand for these services. Most of the world's religions place particular emphasis on the total care of the child. In the context of the overwhelming evidence, the involvement of religious teachings in the promotion of breastfeeding is quite debatable. It is well established that religious ideologies influence the human mind and a person's way of living.

Health professionals traditionally encourage mothers to breastfeed by giving information on benefits of breastfeeding for the infant and the mother herself. The behavior of women can be easily modified through religious teachings in a positive way. Breastfeeding may be affected by religious ideologies using the doctrine in religious texts. Counseling the mothers by reinforcing the cultural and religious practices supporting breastfeeding can help enormously. Use of local religious teachings can bring positive changes in the implementation of health programs [14]. In addition, public nutrition education that promotes infant and young child feeding as defined by WHO, taking into account social-cultural factors is needed and recommended.

\section{References}

[1] World Health Organization. Infant and Young Child Feeding: Model Chapter for Textbooks for Medical Students and Allied Health Professionals. France: World Health Organization, 2009. 
[2] Ten steps to successful Breastfeeding. UNICEF/WHO Baby Friendly Hospital Initiative (BFHI). Initiation of breastfeeding by breast crawl. Available at: http://breastcrawl.org/10steps.shtml.

[3] Black RE, Morris SS, Bryce J. Where and why are 10 million children dying every year? Lancet 2003; 361: 2226-34.

[4] WHO. Effect of breastfeeding on infant and child mortality due to infectious diseases in less developed countries: a pooled analysis. Collaborative Study Team on the role of breastfeeding on the prevention of infant mortality. Lancet 2000; 355: 451-5.

[5] Butte NF, Lopez-Alarcon MG, Garza C. Nutrient Adequacy of Exclusive Breastfeeding for the Term Infant during the First Six Months of Life. Geneva: World Health Organization, 2002.

[6] Jones G, Steketee RW, Black RE, Bhutta ZA, Morris SS. Bellagio Child Survival Study Group. How many child deaths can we prevent this year? Lancet 2003; 362: 65-71.

[7] WHO. Implementing the Global Strategy for Infant \& Young Child Feeding. Geneva, 3-5 Feb, 2003.

[8] Government of India. National Guidelines on Infant and Young Child Feeding. Ministry of Human Resource development, New Delhi; Department of Women and Child development, 9-10, 2006.

[9] Bangladesh Demographic and Health Survey 2014.
[10] The Multiple Indicator Cluster Survey 2012-13 (MICS-2012-13) by Bangladesh Bureau of Statistics and UNICEF, Bangladesh.

[11] Indicators for Assessing Infant and Young Child Feed- ing Practices: Conclusions of a Consensus Meeting Held 6-8 November 2007 in Washington, DC, USA. World Health Organization (WHO), 2008. Available at: http://whqlibdoc.who.int/publications/2008/9789241596664_eng.p df (last accessed on Apr 29, 2012).

[12] Edmond KM, Kirkwood BR, Amenga-Etego S, Owusu- Agyei S, Hurt LS. Effect of early infant feeding practices on infectionspecific neonatal mortality: an investigation of the causal links with observational data from rural Ghana. Am J ClinNutr2007; 86: 1126-31.

[13] Indicators for Assessing Infant and Young Child Feeding Practices: Conclusions of a Consensus Meeting Held 6-8 November 2007 in Washington, DC, USA. World Health Organization, 2008. Available at:

http://whqlibdoc.who.int/publications/2008/9789241596664_eng.p df (last accessed on Apr 29, 2012).

[14] Iftikhar Alam and Safia Begum (2014) Advocating breastfeeding can religious teachings bring a change? Public Health by Nova Science Publishers pp. 165-167. 